\title{
Connecting a sociology of childhood perspective with the study of child health, illness and wellbeing: introduction
}

\author{
Geraldine Brady, Pam Lowe and Sonja Olin Lauritzen
}

The health and wellbeing of children and young people has been studied from a range of different perspectives in social science and the health sciences as a whole. Much of the research to date has been for or on children and has focused on promoting health, detecting illness and its causes or investigating the social determinants of health. While these make vital contributions to making the world better for children and young people, we would argue there is also a need for research with children, research from a child perspective, to fully understand the meaning and impact of health and illness in children's lives. Furthermore, there is a need to explore the social and cultural contexts of child health that frame the lived experiences of children and their parents. More specifically, there is a need to interrogate the explicit as well as the implicit perceptions of childhood and the child in health policy, perceptions that are reproduced in various health and social practices. The purpose of this issue is to contribute to a further understanding of these issues by bridging developments in the sociology of childhood and the sociology of health and illness.

In the last decades we have seen a growing interest across disciplines in research on children's own experiences and understandings of health and illness. It can be argued that this increasing interest has been stimulated by developments in the sociology of childhood. Through the 1990s a body of work emerged which criticised dominant notions of child development where children were largely depicted as immature and passive objects of socialisation (Burman 1994, Halldén 1991, James and Prout 1997, Qvortrup 1994).

Scholars of the sociology of childhood problematised these notions of the child by theorising the ways in which childhood is socially constructed and understandings of the child vary across different sociocultural contexts. Importantly, the focus was shifted from seeing children as immature becomings on their way to adulthood to a focus on children as beings and as competent actors with a social agency of their own, not only influenced by but also influencing their social worlds (James et al. 1998, James and Prout 1997, Qvortrup 1994). Moreover, by understanding children as a specific social group, attention could be directed at children's rights and the structures that enabled and restricted control over their lives (Alanen and Mayall 2001).

Since these early years, the theoretical positions and central concepts in the sociology of childhood (and its place in sociology) have been, and are, debated (see, for example, Alanen 2014, James 2010, Moran-Ellis 2010). At the same time, empirical studies of children and childhoods have been burgeoning in sociology and in other disciplines.

Although a full account of these developments and disciplinary differences falls outside the scope of this issue, here we want to draw attention to some of the central concepts and theoretical points of departure in this tradition that we find of particular interest for studies of child health and wellbeing.

Firstly, seeing children as a social (minority) group draws our attention to the ways this group is placed and perceived in the structures of societies. Children as a social group need to be understood in relation to other social groups. Importantly, work on children as positioned in intergenerational relations has added to understanding of the dynamics in relations between children, parents and adult society (Mayall 1996, 1998). This involves power relations and the ways children (as a group) are listened to and taken account of in different social settings, such as in healthcare settings and at school, but also prevailing discourses and images of the child in social and health policy and health promotion interventions addressing children and young people.

Secondly, understanding children as social agents and as co-constructors of their social worlds is fundamental to studying their experiences and ways of dealing with health and wellbeing in everyday life. Child agency is a core issue in the sociology of childhood, but it has also been debated in this tradition in recent years. Agency is not to be seen as just something positive, or a personal competence, but as a more complex and multidimensional concept 
(Valentine 2011). Children's agency is bounded by and in intergenerational relations as well as in wider socioeconomic contexts and bodily, social and material resources. This raises questions about whose actions should impact on whom (Tisdall and Punch 2012). Power and participation are situated and changeable, which calls for attention to how children's agency is perceived, facilitated and restrained in specific settings.

Thirdly, in recent years, there has been a turn towards seeing children as beings (not just becomings). However, it is also argued that all humans are becomings; subjects who develop and change as they experience the world and in relation to different social contexts (Lee 2001, 2005, Prout 2005, Uprichard 2008). Further, there is an issue with diversity and variation in children's lives. There is no typical child. Children are of different ages, gender, ethnicity, socioeconomic circumstances and capacity. They live in different national and cultural contexts and attend different educational institutions. Thus, they are subject to different structures and discourses on children and childhoods (Prout 2005). Increasingly, conceptualisations of the child that homogenise and decontextualise children and their lives are being viewed as problematic (see, for example, Singal and Muthukrishna, 2014).

We argue that there is a need to reflect more broadly on learning from the sociology of childhood in research on child health. This tradition is now well established and there is much evidence to indicate that children are competent social actors, yet we are in agreement with Tisdall and Punch when they state that:

Focusing on children and young people's perspectives, agency and participation is no longer sufficient; greater emphasis is needed on the intricacies, complexities, tensions, ambiguities and ambivalences of children and young people's lives across both Majority and Minority World contexts. (2012: 22)

These issues also raise questions about research methodology. The risk of homogenising and decontextualising children also applies to the context of research on children's lives. If it is important to do research with children, how do we locate children at the centre of knowledge production? How can we access children's perspectives and lived experience? One avenue suggested is to use a range of methods to take account of diversity between children (see, for example, Christensen and James 2000) or to involve children as actors in research as a way to overcome the power imbalance between the child and the researcher (Alderson 2000, Mason and Hood 2011) which, however, might create new methodological problems (Harden et al. 2000). On the other hand, whether research with children is necessarily different from research with adults is also being questioned. 'If children are competent social actors, why are special "child-friendly methods" needed to communicate with them?' (Punch 2002: 321). These, and other methodological issues are part and parcel of research with children and need to be addressed to obtain a child's perspective on health and wellbeing.

So, what are the child health issues and concerns in contemporary society? Children are diagnosed with an increasing range of conditions and are subject to more and more elaborate child health and welfare interventions, reflecting a medical perspective on the changing panorama of illness and health risks in the 21st century. We see today a growing concern with mental health (for example, the autistic spectrum), as well as emerging contested illnesses (attention deficit hyperactivity disorder [ADHD]), life-style related conditions (obesity and allergies) or 'new' infectious diseases (HIV/AIDS). However, we would argue that in trying to bridge the sociology of childhood with that of health and illness, it is important to look beyond what is discussed as child health issues and take account of issues currently debated in the sociology of health and illness more generally. Health behaviour approaches have almost universally been adopted by those involved in healthcare research, with little critical attention paid to the conceptualization of health behaviour (Cohn, 2014). The assumption that there are easily identifiable and observable forms of health behaviour can be difficult to challenge, not least because the way in which health behaviours are seen as the outcome of individual choices has become established as the norm. This model also draws on ideas about agency, particularly in relation to choice and personal responsibility, often devoid of the social, economic and political context in which such agency is being enacted. In addition, a focus on health risks and surveillance medicine, as well as on lay understandings and patient perspectives, are relevant in the study of child health. However, research on these health issues, similarly to the old issues of chronic or life threatening illness, have largely been limited to the taken-for-granted adult person (Williams 2000). Expanding research to other phases of the life-course to include childhood is important not only to understand the meaning of child health and children's experiences but also to add important knowledge at a more general level to the understandings of health and illness. 


\section{Themes of this issue}

As outlined above, in this issue we focus on the ways that socially and culturally constructed understandings and conceptualisations of childhood impact on issues of health and well-being and on the ways in which children exercise agency and competence in dealing with health and illness. A further consideration is how agency is bounded in intergenerational relations; while the focus of this issue is on children, the role of parents as mediators and facilitators in the healthcare division of labour (Stacey 1988, Mayall 1996) cannot be underestimated. Further, health, we argue, can be understood only by locating children as embodied beings (Bendelow 2009) in different social and cultural contexts. To advance our understandings of child health, it is necessary to situate child health issues in wider social, economic, cultural and national contexts as well as in the variety of public and social policies that will impact on dominant ways of understanding childhood and on children's lives and opportunities.

Children's daily lives play out across the social contexts which structure their lives. The settings of school and home largely organise children's lives, while their movement between such settings straddles the public and private domains. Messages about health are communicated to children both explicitly and implicitly so that they begin to learn social norms around health and, sometimes, change their behaviour in response to such messages. Mayall has argued that 'child health is not a neutral, factual concept; notions of child health are constructed out of essentially political considerations' (Mayall 1996:22). It may be assumed that children are relatively passive and conforming when faced with illness or diagnoses, yet children do exercise choices. Children have an active role in the management of health risks, their conditions and interactions with healthcare services. Moreover, they develop a repertoire of strategies to cope and sometimes to resist adult defined agendas (Bluebond-Langner 1978, 1996). Adults can be unaware of the ways in which children are interpreting information on health and making it meaningful to their lives. Previous health research has shown that even chronologically young children are competent reporters of their illness experiences (Alderson 1993) and that children can understand complex information if it is presented in appropriate ways (Alderson and Goodey 1996).

Since Mayall's 1998 article in this journal calling for a sociology of child health, research published in this area has increased but is sometimes disparately located. In this issue, the aim is to contribute to the development of a sociology of child health by bringing together current research that draws on the sociology of childhood and to address three cross-cutting themes that we have identified as being important in the study of child health and wellbeing:

Theme 1: situating children within health policy, which sets out the significance and pervasive influence of health policy in shaping the lives of children and their families.

Theme 2: practices of children's health and wellbeing, which focuses on health policy in action by looking at interactions between professionals, parents and children.

Theme 3: children as health actors, with a specific focus on the lived experiences of children and young people themselves.

Taken together, these three themes can offer examples of differing contexts and encourage reflection on current and culturally specific ways of knowing and understanding children's health.

\section{Theme 1: situating children within health policy}

The health of the child is seen as a signifier for the current and future health of the nation, placing their bodies at the intersection of ideas about social order. Armstrong's (1995) influential work on surveillance medicine clarified how this new 20th century medical paradigm became particularly concerned with the child and child development, over time and into the future. Children are thus a critical object of state policy, where the main focus is on children as future citizens (Mayall 1998), (which raises questions as to whether the future-focus of policy is always in the best interests of children in the here and now). The health policy focus is on risks and includes a preoccupation with children's body size, development and behaviour. These developments are reflected in an increase in preventive medicine and various programmes for health promotion as well as early detection and intervention in groups of people considered to be at risk, to a large extent directed at children and their parents. While surveillance of child health is not new, it is important to understanding the ways in which children are categorised as healthy or ill, normal or deviant; categorisations that contribute to shaping the embodied lives of children and young people. For 
example, research on medicalisation as well as psychiatrisation of child development and behaviour (Le Francois and Coppock 2014), followed by pharmaceuticalisation (Williams et al. 2011) has raised the question of how categories of child deviance are constructed in the process of health surveillance and also how diagnosis can function as a tool to categorise individuals (Jutel 2009).

Health promotion information aimed at parents often raises awareness of risk and also of protective factors - it is professed that knowing about risks can help parents to consider the best ways of supporting and optimising the wellbeing of children. The risk is usually described as potentially increasing the likelihood of a child or young person developing physical, mental or social difficulties. One main issue with this kind of approach is that many of the factors that put children at risk are not amenable to change by families as they are structural factors such as poverty, stigmatisation and the poor provision of education and welfare. Not being in a position to minimise such risks, coupled with the emphasis on their long-term consequences for children, can leave parents feeling inadequate and also contributes to the depoliticisation and individualisation of social problems (Conrad 1976, Zola 1972).

Against this backdrop, and in a world of health and social inequalities, a critical engagement with the ways in which health policy and practice impacts on children is required. It is also important to analyse the ideas and images of children and childhood present in policy documents and health interventions. Such ideas and images are typically taken for granted, but in-depth analyses of child health policy documents and programmes tell us something about the prevailing understandings of the child in our societies. It also reveals the ways in which deviance from perceived norms becomes a matter for concern and intervention. The ways in which child health and normality are reflected in health policy and practice thus have implications for children and young people as well as their parents and carers.

\section{Theme 2: practices of children's health and wellbeing}

In a sociological approach to health, health care is recognised as part of a social process, carried out in the public domain by paid professionals and privately by unpaid, lay carers (Stacey 1988). Health may also be understood variously; for example, professional beliefs may differ from lay beliefs, adult beliefs may differ from children's beliefs and all are variously influenced by a range of factors. Understandings of child health are thus to be seen as relational and constructed in communication between different actors in everyday life. Also, ideas about child health and how children should be treated vary across social and cultural contexts both in and between different societies, not least between the global North and South, which stresses the importance of seeing children's health and wellbeing as contextually embedded (Singal and Muthukrishna 2014).

As we cannot assume a linear relationship between policy and practice, it is important to consider how health policy becomes translated into practice in healthcare encounters at different levels: in surveillance and intervention programmes directed at children and young people (or those considered to be at risk) - initiated and carried out by the social and health services - and at the level of the clinical encounter initiated by parents (or others) to deal with the health and illness of the individual child.

Sociology of health and illness research has shed light on the impact of surveillance medicine and has demonstrated how messages of normality and deviance are communicated explicitly as well as implicitly when carried out in health practice (Olin Lauritzen and Sachs 2001). But we still need to know more about the content of these messages. What are the ideas about childhood and the child as well as ideas about normality and deviance inherent in surveillance and intervention and communicated to children and parents? Also, the changing panorama of what is considered a deviance from normal development and behaviour in children needs to be addressed, as well as the fact that the surveillance and monitoring of children's minds and bodies is carried out from an adult perspective and children are not always asked about their views or included in decision-making about their care.

At the level of clinical encounters between professionals, parents and children in various healthcare settings, the different voices of these parties can be identified and intergenerational aspects and power relations of the interaction can be laid bare and examined. Early work by Strong (1979) and Silverman (1987) explored the details of how the degree of 'medical doubt' concerning the health of the child patient created different formats of the clinical encounter. This has been followed by studies of how professional and moral understandings and disciplinary frameworks, as well as the structural organisation of healthcare, shape healthcare encounters and the power relations in these encounters (White 2002). 
Detailed micro analyses have shed further light on the dynamics of the interaction and power relations between health professionals, parents and children - including the ways in which children contribute to or are excluded in these processes (Aronsson and Rundström 1988, Clemente 2009). Dimond (2014) argues that research on the triadic relationship between children, parents and healthcare professionals in clinical settings is much needed to help to enhance understanding. From what is known about the role of adults in health encounters they often dismiss or reframe children's own bodily sensations and experiences (Carter 2002) to fit existing frameworks of understanding. When it comes to children's voices and agency in healthcare interaction, important contributions have been made, for instance, on children's consent to treatment (Alderson 1993, Alderson and Goodey 1996) but more knowledge is needed to explore children's experiences and capacities. Importantly, patterns of interaction and power dynamics in health practices need to be explored further from a child perspective and across different sociocultural contexts.

\section{Theme 3 - Children as health actors}

The third theme of this issue focuses specifically on children's own experiences of health and illness, of living with a condition and on children's active participation in the management of their bodies and minds. Exploring the lived experience of children brings to the fore their role as healthcare actors. We acknowledge that in the field of child health, the views of children, as service users, are beginning to be sought, often through consultation or evaluation. However, perhaps unsurprisingly, the social and political context of lay/professional, adult/child interaction and embedded social relations and structures are often not explicated thoroughly enough to provide a deeper understanding of the experience of children. Consequently, the data gained from such exercises can be superficial. Crucially, we cannot fully understand the impact and meaning of health and illness in children's lives without bringing in children's experiences, understandings, competence and agency in dealing with these issues (Mayall $1996,1998)$. Examples that show this is possible include studies that have accessed the views of children over a range of areas such as in relation to doctor-patient consultations (Rindstedt 2014), the design of children's health services and spaces (Birch et al. 2007) and treatment preferences and their impact (Coad 2010). It is clear that by using a range of different methodological approaches, research can show how children's concerns often differ from adult-centred ones.

One important issue in the lives of children and young people is the social implication and impact of receiving a medical diagnosis. This can have both negative and positive effects on children's identity and embodied lives, both from their own perspective and the way that they are seen by others. Earlier research in this field has indicated that children's competence and understanding in dealing with a medical diagnosis is often underestimated (Berntsson et al. 2007, Brady 2005). This may particularly be the case where definitions are contested or there are debates over prevention or treatment. Questions are raised about children's own priorities, concerns and agendas and how they can be in conflict with those of adults (Brady 2014, Williams et al. 2007).

Children's and young people's experiences and understandings of health, illness and medical interventions are interesting per se. Moreover, children's understandings also have implications for how they act to promote health, how they deal with illness and manage risks to their health in everyday life. On the one hand, 'Children use their resourcefulness to stretch adult-imposed boundaries to limits more acceptable to themselves' (Punch 2001: 34), a fact that is especially evident in research into children's management of risks and of medication. On the other hand, children's dealing with health and illness has to be understood relationally: being healthy or ill, competent or not, takes place, so to say, in relation to others and in the complexity of local contexts. There is also a spatial dimension to consideration of children's health in that a number of sites of health practices, including early year childcare settings, school (the classroom and playground), the family home and wider public space are of importance.

\section{Introduction to the collection of articles}

This collection of articles, all anchored in a sociology of childhood perspective, include contributions from a range of disciplines, countries and sociocultural contexts as well as different methodological approaches. They address different cases of health policy and practice as well as children's (and parent's) experiences of a range of conditions and ways of 'doing health.'

The first articles address the ways in which children are positioned in health policy. In their article, Bergnéhr and Zetterqvist Nelson take mental-health-promoting interventions to explore the ways in which children are situated in health policy; how young people are viewed, understood, thought about and positioned. While this research 
analyses the Nordic context, such public health interventions are increasingly being introduced to children and young people across the world. Two themes thread through the analysis - that the child is largely assumed to be passive and formed by adults and that ideas about health and wellbeing are often highly individualised and decontextualised. These themes appear throughout the issue. The study draws attention to school as a site of health promotion and maintenance and argues for a need to know more about children's experiences of such (mental) health interventions, which are largely normalised and seen as part of school life in some countries.

In the next article, Lowe, Lee and MacVarish focus on images of children and parents in health policy documents, more specifically on 'brain claims' in English health and welfare policies from 1998 to 2012. The authors describe how determinist ideas about brain development, drawing on quasi-neuro-scientific discourses, are becoming prevalent in understandings of children and child development. They discuss this development as a drive in policy that amounts to understanding children's development and growth in increasingly narrow terms. Although focused on England in this instance, it is argued that such brain claims are impacting on policy and practice across the western, neoliberal world. Taken together, these two articles demonstrate how a detailed analysis of health policy documents and programmes can reveal implicit ideas about the child; ideas that will impact on practice and are translated in communication with parents and children.

The articles that follow focus precisely on such practices, and on the complex dynamics in the translation and communication of notions of the child as well as the divides between health, illness or deviance from the norm. Research undertaken by Martin focuses on public health messages of concern and panic about childhood obesity and explores how the issues of obesity and additional weight are understood by children and their mothers in Malta. By ethnographically studying the children in a primary school setting she is able to identify the subtle ways in which children understand and depict their own bodies (as fat or not), as well as highlighting interesting differences between the bodily accounts given by younger children (5-year olds) and those somewhat older (10-year olds). She argues that the younger children are buffered by robust protective strategies in their group, while children in the older group perceive themselves to be different and are indeed so labelled; they develop private coping strategies to manage the levels of exclusion often felt. In doing this, Martin draws attention to the ways children's bodies are both biologically and socially constructed.

Also in this issue, Alexander, Fusco and Frohlich begin by acknowledging increasing public health concerns about childhood obesity. In Canada, public health institutions are emphasising active play as a way of combatting obesity. The article highlights the contrast between public health discourses and children's own diverse, lived experiences of playing. They show how some children adopted the understanding of active play, while others highlighted the importance of other more sedentary activities. They argue that there may be unintentional consequences in limiting understandings of play to an active mode. This article again highlights the need to properly understand the children's lives before interventions are planned and executed. Both of these studies relating to obesity highlight the ways in which messages on one of the major public health issues in the Western world are communicated, taken up and understood by children and their parents.

The following article, by Wilhelmsen and Dyblie-Nilsen also explores the practices of children's health and wellbeing. In this case the focus is on how normal child development is communicated to parents in an early years setting, in a Norwegian day-care centre. The article addresses the processes and tools used to assess and define children's behaviour as either normal or deviant. The article shows the complexity of parents' experiences of pathways towards a diagnosis of a non-normal condition, such as ADHD, and a 'special-needs' designation. Parents have their everyday understanding of their child, which may agree or disagree with the professional perspective. In their study they also show how forms and charts used to map behaviour serve to provide a visual representation of deviance and difference and are regarded as evidence, legitimating the forms of power at work in the social construction of knowledge.

The following three contributions address the understandings and experiences of children and young people who are living with different conditions. Mogensen and Mason consider the label of autism and the meaning of this diagnosis to a group of five young people in Australia. The young people were able to choose how they communicated with the researchers, who used participatory research methods, and were able to share their understandings of autism and its impact on their sense of self and identity. More specifically, the authors show how 
the young people integrated their understandings of the autism diagnosis with their sense of self, and the different positive or negative meanings the diagnosis could take on in this process. Also, these young people clearly desired to be in control of the ways in which they dealt with their diagnosis, and Mogensen and Mason suggest that ways of minimising stigma and marginalisation associated with a diagnosis of autism need to be considered at a policy level.

Bernays, Seeley, Rhodes and Mupambireyi also explore children as health actors, in this case the illness narratives of children living with HIV and accessing antiretroviral treatment (ART). They note that in previous research into HIV, adult views have been the focus, acting as proxy representations of the experience of children. The narratives told by the children themselves reveal a complex picture of illness stories, resistance to being defined as ill, and what the authors identify as protest talk - where children strive to come to terms with the ambiguities of being regarded as sick while feeling and looking well. Their narratives illuminate the challenge involved in achieving a sense of normalcy. Importantly, this article highlights the social challenges which accompany long-term adherence to treatment (in this case ART), a theme that is also relevant to other articles in this collection.

Stjerna's paper on the management of food allergy, a potentially life threatening condition, brings to the fore debates about risks to children's health. A study of young Swedish people with a food allergy highlights how the everyday management of this condition is contending with health risks as well as social risks, the risk of a severe bodily reaction as well as of being seen as different by their peers or others when trying to avoid 'dangerous' food or using medication. Not only is risk involved here but also issue of trust and responsibility. This article sheds light on the relational elements of the agency of the young people in the management of their condition, in the ways they are dependent on contexts, environments and the behaviour of other people. Researchers are adopting various methods and methodologies in order to understand the perspectives of children. Jenkins discusses a micro-analysis of children as health actors, drawing on a study that focuses on the interaction that takes place between children and their parents in the family home. Analysis of video recordings of English family mealtimes reveals the ways in which children express bodily sensations, which are often redefined or denied by parents. Using conversation analysis to drill down into the interactions the article draws attention to the agency of children. In investigating the rights of children to report on their own embodied experience it adds to our understanding of the enactment of power dynamics in families and raises questions about the ways in which, from an early age, children's own experiences are denied or shaped by more dominant adult understandings which make claims to meaning.

The final article is a fitting contribution from Mayall, who originally called for a sociology of child health in 1998. Building on her previous theoretical and empirical research on the status of childhood, she discusses developments in the sociology of childhood and reflects on possible avenues for future research. She makes explicit the minority status of children and positions children in intergenerational relations by drawing attention to bodily relations between adults and children, particularly focusing on ideas about the body that structure children's experiences of their bodies and emotions. This article focuses on health and wellbeing, rather than illness or sickness, and points out that 'Wellbeing is associated with being a valued and respected person.'

Spanning the three key themes, the articles in this collection contribute to a critical analysis of child health policy and notions of child health and normality, as well as to our understandings of the active contributions children make to deal with health and illness in their own lives. Through analysing the relationship between concepts of child health and illness - as they are represented in health policy, discourse and dominant understandings - and children's actual lived experiences, a sociological lens is afforded that helps to illuminate the complexities of structure and agency as well as the interaction between biological and social processes.

These articles show how a focus on childhood health can be an appropriate vehicle to appreciate the ways children uniquely experience their childhood while being part of the structural category of a generation. In exploring the lifeworlds of a range of children, these research accounts show that there is little that is universal about 'the child' and it is more appropriate to refer to a variety of childhoods, which draws our attention to the importance of not uncritically adopting Western values in research and health policy globally. These predominantly empirical contributions, carried out in different sociocultural contexts, are much needed to contribute to a more substantial volume of research on child health from a sociology of childhood perspective and to generate further developments at a theoretical level. 
To conclude, the articles presented here suggest theoretical and empirical research potential for a sociology of children's health and illness. The collection thus goes some way to seriously beginning to address the migration of the sociology of child health from the margins into the mainstream of sociology of health and illness. In the endeavour to promote the social study of child health, it is, of course, also important to take account of contributions from neighbouring fields such as childhood geographies, child disability studies, studies of children's play and others that we have not been able to include in this issue. Finally, we hope that this issue will encourage productive debate among a wide audience, including academics as well as policy-makers, healthcare professionals and people who are involved with children, and young people and their parents in everyday life.

References

Alanen, L. (2014) Editorial: theorizing childhood, Childhood, 21, 1, 3-6.

Alanen, L. and Mayall, B. (2001) Conceptualising Child Adult Relations. London: Routledge and Falmer.

Alderson, P. (1993) Children's Consent to Surgery. Buckingham: Open University Press.

Alderson, P. (2000) Children as researchers: the effects of participation rights on research methodology. In Christensen, P. and James, A. (eds) Research with Children: Perspectives and Practice. London: Falmer Press.

Alderson, P. and Goodey, C. (1996) Research with disabled children: how useful is child-centred ethics? Children \& Society, 10, 2, 106-116.

Armstrong, D. (1995) The rise of surveillance medicine, Sociology of Health \& Illness, 17, 3, 393-404.

Aronsson, K. and Rundström, B. (1988) Child discourse and parental control in paediatric consultations, Text and Talk, 8, 3, 15989.

Bendelow, G. (2009) Health, Emotion and the Body. London: Polity Press.

Berntsson, L., Berg, M., Brydolf, M. and Hellstrom, A.L. (2007) Adolescents' experiences of well-being when living with a long term illness or disability, Scandinavian Journal of Caring Sciences, 21, 4, 419-25.

Birch, J., Curtis, P. and James, A. (2007) Sense and sensibilities: in search of the child friendly hospital, Built Environment, 33, 4, 2, 405-16.

Bluebond-Langner, M. (1978) The Private Worlds of Dying Children. Princeton: Princeton University Press.

Bluebond-Langner, M. (1996) In the Shadow of Illness. Parents and siblings of the chronically ill child. Princeton: Princeton University Press.

Brady, G. (2005) ADHD, diagnosis and identity. In Newnes, C. and Radcliffe, N. (eds) Making and Breaking Children's Lives. Rosson-Wye: PCCS Books.

Brady, G. (2014) Children and ADHD: seeking control within the constraints of diagnosis, Children \& Society, 28, 3, 218-30.

Burman, E. (1994) Deconstructing Developmental Psychology. London: Routledge.

Carter, B. (2002) Chronic pain in childhood and the medical encounter: professional ventriloquism and hidden voices, Qualitative Health Research, 12, 1, 28-41.

Clemente, I. (2009) Progressivity and participation: children's management of parental assistance in paediatric chronic pain encounters, Sociology of Health \& Illness, 31, 6, 872-8.

Coad, J. (2010) The Impact of Cancer on a Child's World: the Views of Children Aged 7-13 Living with and Beyond Cancer. London: CLIC Sargent.

Cohn, S. (2014) From health behaviours to health practices: critical perspectives, Sociology of Health \& IIIness, 36, 2, 1-6.

Conrad, P. (1976) Identifying Hyperactive Children: the Medicalisation of Deviant Behaviour. Lexington: Lexington books.

Christensen, P. and James, A. (eds) (2000) Research with Children: Perspectives and Practice. London: Falmer Press.

Dimond, R. (2014) Negotiating identity at the intersection of paediatric and genetic medicine: the parent as facilitator, narrator and patient, Sociology of Health \& Illness, 36, 1, 1-14.

Halldén, G. (1991) The child as a project and the child as being: parents' ideas as frame of reference, Childhood and Society, 5, 4, 334-46.

Harden, J., Scott, S., Backett-Milburn, K. and Jackson, S. (2000) 'Can't talk, won't talk?' Methodological issues in researching children, Sociological Research Online, 5, 2. Available at www.socresonline.org.uk/5/2/harden.html (accessed 25 January 2015).

James, A. (2010) Competition or integration? The next step in childhood studies? Childhood, 17, 4, 485-499. 
James, A. and Prout, A. (1997) Constructing and Reconstructing Childhood. London: Falmer.

James, A., Jenks, C. and Prout, A. (1998) Theorising Childhood. Cambridge: Polity Press.

Jutel, A. (2009) Sociology of diagnosis: a preliminary review, Sociology of Health \& Illness, 31, 2, 278-99.

Le Francois, B. and Coppock, V. (2014) Psychiatrised children and their rights: starting the conversation, Children and Society, 28, 3, 165-256.

Lee, N. (2001) Childhood and Society: Growing Up in an Age of Uncertainty. Buckingham: Open University Press.

Lee, N. (2005) Childhood and Human Value: Development, Separation and Separability. Maidenhead: Open University.

Mason, J. and Hood, S. (2011) Exploring issues of children as actors in social research, Children and Youth Service Review, 33, 4, 490-5.

Mayall, B. (1996) Children, Health and the Social Order. Buckingham: Open University Press.

Mayall, B. (1998) Towards a sociology of child health, Sociology of Health \& Illness, 20, 3, 269-88.

Moran-Ellis, J. (2010) Reflections on the sociology of childhood in the UK, Current Sociology, 58, 2, $186-205$.

Olin Lauritzen, S. and Sachs, L. (2001) Normality, risk and the future: implicit communication of threat in health surveillance, Sociology of Health \& Illness, 23, 4, 497-516.

Prout, A. (2005) The Future of Childhood. London: Routledge Falmer.

Punch, S. (2001) Negotiating autonomy: childhoods in rural Bolivia. In Alanen, L. and Mayall, B. (eds) Conceptualising Child-Adult Relations. London: Routledge.

Punch, S. (2002) Research with children: the same or different from research with adults, Childhood, 9, 3, 321-40.

Qvortrup, J. (1994) Childhood matters: an introduction. In Qvortrup, J., Bardy, M., Sgritta, G. and Wintersberger, H. (eds) Childhood Matters: Social Theory, Practice and Politics. Avebury: Ashgate.

Rindstedt, C. (2014) Children's strategies to handle cancer: a video ethnography of imaginal coping, Child: Care, Health and Development, 40, 4, 580-6.

Silverman, D. (1987) Communication and Medical Practice. Social Relations in the Clinic. London: Sage.

Singal, N. and Muthukrishna, N. (2014) Education, childhood and disability in countries in the South - re-positioning the debates, Childhood, 21, 3, 293-307.

Stacey, M. (1988) The Sociology of Health and Healing: a Textbook. London: Routledge.

Strong, P. (1979) The Ceremonial Order of the Clinic. Parents, Doctors and Medical Bureaucracies. London: Routledge and Kegan Paul.

Tisdall, K. and Punch, S. (2012) Not so new? Looking critically at childhood studies, Children's Geographies, 10, 3, $249-64$.

Uprichard, E. (2008) Children as 'being and becomings': children, childhood and temporality, Children \& Society, 22, 4, 303-13.

Valentine, K. (2011) Accounting for agency, Children \& Society, 25, 5, 347-58.

White, S. (2002) Accomplishing 'the case' in paediatrics and child health: medicine and morality in inter-professional talk, Sociology of Health \& Illness, 24, 4, 409-35.

Williams, S. (2000) Chronic illness as biographical disruption or biographical disruption as chronic illness?: reflections on a core concept. Sociology of Health \& Illness, 22, 1, 40-67.

Williams, S., Lowe, P. and Griffiths, F. (2007) Embodying and embedding children's sleep: some sociological comments and observations, Sociological Research Online, 12, 5. Available at www.socresonline.org.uk/12/5/6.html (accessed 25 January 2015).

Williams, S., Martin, P. and Gabe, J. (2011) The Pharmaceuticalisation of Society: a framework for analysis, Sociology of Health \& Illness, 33, 5, 710-25.

Zola, I. K. (1972) Medicine as an institute of social control, Sociological Review, 20, 4, 487-503. 